\title{
Negar la cotidianidad: una propuesta epistémica para la Terapia Ocupacional a partir de una autoetnografía de la revuelta popular en Chile
}

Denying everyday life: an epistemic proposal for Occupational Therapy based on an autoethnography of the popular revolt in Chile

Negando o cotidiano: uma proposta epistêmica para a Terapia Ocupacional a partir de uma autoetnografia da revolta popular no Chile

Débora Grandón Valenzuela'

Recibido: 14 de agosto 2020 • Enviado para modificación: 27 de septiembre 2020 • Aceptado: 30 de noviembre 2020

Grandón-Valenzuela, D. (2020). Negar la cotidianidad: una propuesta epistémica para la terapia ocupacional a partir de una autoetnografía de la revuelta popular en Chile. Revista Ocupación Humana, 20(2), 25-46. https://doi. org/10.25214/25907816.881

\section{RESUMEN}

Considerando el creciente interés y el desarrollo que el concepto de cotidiano ha tenido en la Terapia Ocupacional latinoamericana desde la década de los 90, aproximadamente, este artículo propone el ejercicio de articular conceptualizaciones teórico-críticas sobre lo cotidiano mediante el análisis de la revuelta popular chilena, iniciada en octubre del 2019. Dicha articulación toma como eje el concepto de cotidianidad intolerable, buscando relevar la construcción histórica y política de la vida que se presenta como normal, al tiempo que reproduce formas de vida precarizadas e intolerables. Metodológicamente, este ejercicio se realizó a través de una autoetnografía que incluye narraciones y fotografías, a partir de la participación de la autora como activa manifestante durante 22 jornadas de protesta y actos culturales desarrollados en Santiago de Chile entre octubre del 2019 y marzo del 2020. Se resalta cómo la negación de lo cotidiano posibilita una apertura para pensar críticamente las condiciones de vida, evidenciando su textura de entramados complejos de relaciones de poder. Finalmente,

1 Terapeuta ocupacional. Maestra en Estudios de Género y Cultura. Doctoranda en Estudios Latinoamericanos, Universidad de Chile. Docente, Departamento de Terapia Ocupacional y Ciencia de la Ocupación, Universidad de Chile. Santiago de Chile, Chile. dlunagrandon@gmail.com iD https://orcid. org/0000-0001-8709-2902 
se propone lo cotidiano como un desplazamiento epistémico para la Terapia Ocupacional, reconociendo la potencia política de las ocupaciones y las actividades humanas.

\title{
PALABRAS CLAVE
}

América Latina, capitalismo, movimiento de protesta, participación política, Terapia Ocupacional, vida cotidiana

\begin{abstract}
Considering the growing interest and development that the concept of quotidian has had in Latin American Occupational Therapy since the 90s, this article proposes articulating theoretical-critical conceptualizations about the everyday through the analysis of the Chilean popular revolt, which started in October 2019. The axis of this articulation is the concept of intolerable routine, looking to substitute the historical and political construct of what everyday life is and, at the same time, reproduces precarious and intolerable forms of living. Methodologically, this exercise was carried out through an autoethnography that includes narrations and photographs from the author's participation as an active protester during 22 days of protest and cultural manifestations held in Santiago de Chile, between October 2019 and March 2020. This reflective exercise highlights how the negation of everydayness allows an opening to critical thinking about living conditions, evidencing its texture of complex networks of power relations. Finally, it proposes the everyday as an epistemic shift for occupational therapy, recognizing the political power of human occupations and activities.
\end{abstract}

\section{KEYWORDS}

Latin America, capitalism, protest movements, political participation, Occupational Therapy, everyday life

\section{RESUMO}

Considerando o crescente interesse e desenvolvimento que o conceito de cotidiano teve na Terapia Ocupacional latino-americana, desde a década dos anos 90, aproximadamente, este artigo propõe o exercício de articular conceituações teórico-críticas sobre o cotidiano por meio da análise da revolta popular chilena, iniciada em outubro de 2019. Essa articulação toma como eixo o conceito de cotidiano intolerável, buscando socorrer a construção histórica e política da vida que se apresenta como normal, reproduzindo modos de vida precários e intoleráveis. Metodologicamente, este exercício foi realizado por meio de uma autoetnografia, que inclui narrações e fotografias, a partir da participação do autor como manifestante ativo durante 22 dias de protesto e eventos culturais realizados em Santiago do Chile, entre outubro de 2019 e março de 2020. Destaca-se como a negação do cotidiano permite uma abertura para pensar criticamente as condições de vida, mostrando sua textura de complexas redes de relações de poder. Por fim, o conceito de cotidiano é proposto como uma mudança epistêmica para a Terapia Ocupacional, reconhecendo o poder político das ocupações e atividades humanas.

\section{PALAVRAS-CHAVE}

América latina, capitalismo, movimento de protesto, participação política, Terapia Ocupacional, vida cotidiana 


\section{Introducción}

La vida cotidiana se ha convertido en las últimas décadas en un objeto analítico de gran interés para la producción académica de la Terapia Ocupacional en Latinoamérica. Si bien su inclusión como objeto de estudio no es nueva, podría decirse que en las corrientes teóricas asociadas a la transmisión anglosajona ${ }^{2}$, la cotidianidad ha adoptado una estructura técnica y positivista, bajo la tipificación de actividades de la vida diaria fragmentadas y ahistóricas (Galheigo, 2003, 2012, 2020), que aparecen principalmente como objeto de intervención.

A modo de ejemplo, Galheigo (2012) reconoce la difícil adopción del concepto de ocupación en Brasil por su asociación con la ocupación de territorios, o bien, con actividades menores relacionadas con el tiempo libre. En esta tensión, el concepto de actividad primó en la profesión y por lo general se utilizó indistintamente en variadas posturas epistemológicas, siempre acompañada de algún adjetivo (actividad lúdica, artística, creativa, etc.).

Según esta autora, fue solo hasta los años 90 cuando el concepto de cotidiano fue apropiado por la profesión en Brasil, fundamentalmente por dos motivos. En primer lugar, por la época circulaban y estaban en auge los estudios críticos sobre la vida cotidiana de Ágnes Heller, Henri Lefèbvre y Georg Lúkacs. Por otra parte, el reconocimiento de las condiciones concretas de existencia de los sujetos por la Terapia Ocupacional posibilitó el uso del concepto de cotidiano, expresando así una posición epistemológica crítica e histórica que retomó la relación sujeto-historia (Galheigo, 2003, 2012, 2020).

Lo cotidiano como conceptualización histórica se contrapone a aquella tradición anglosajona que ha instrumentalizado la vida humana a través de una serie de dimensiones y actividades que la reducen a los estratos biológico y funcional, operación política que establece una verdad del cuerpo, en el primer caso, y un uso económico de este, en el segundo. Ante ello, cobra sentido retomar aquel cuestionamiento que ya en 1988 sostenía Berenice Rosa Francisco (citada por Galheigo, 2020), al señalar que esta visión funcionalista ha llevado a la Terapia Ocupacional a operar como un dispositivo de control social que asume a la sociedad como un todo armónico e incuestionable al cual los sujetos deben ser adaptados o normalizados.

Si bien la consideración de la Terapia Ocupacional como dispositivo de control social se ha seguido abordando en algunos trabajos como los de Da Rocha (2008), Herrera y Valderrama (2013, 2014), Guajardo (2014) y Gutiérrez y Pujol (2016), por mencionar algunos, el interés del presente artículo radica

\footnotetext{
${ }^{2}$ Se usa aquí el término anglosajón para referirse a todas aquellas corrientes teóricas asociadas a la lengua inglesa, destacando las producciones que en mayor medida se han vuelto hegemónicas en la transmisión académica de la profesión, como la tradición norteamericana, ligada a la Asociación Americana de Terapia Ocupacional (AOTA, por sus siglas en inglés), y la tradición canadiense, asociada al Modelo Canadiense del Desempeño Ocupacional. Además es necesario considerar que la formación de terapeutas ocupacionales argentinas (y como consencuencia, chilenas), se dio a partir de la contratación de terapeutas ocupacionales inglesas que en 1959 viajaron a Argentina para organizar la formación profesional y la transmisión académica (Botinelli et al., 2016).
} 
en destacar aquella posibilidad crítica y política que lo cotidiano, como concepto y experiencia, abre a la Terapia Ocupacional, a modo de dislocación respecto de aquella tradición hegemónica que la ha producido como dispositivo de control. Lo cotidiano, comprendido como espejo de la historia, nos permite observar la reproducción de un sujeto histórico, y en ello, a las modalidades de su dominación (Heller, 1987); cuestión que permite considerarle un anclaje teórico-conceptual que se opone, no tanto a la ciencia y sus métodos, sino a "los efectos de poder centralizadores que están ligados a la institución y al funcionamiento de un discurso científico organizado en una sociedad como la nuestra" (Foucault, 2000, p. 22-23).

Por ello, a continuación se presentan algunos antecedentes sobre los usos del concepto de cotidiano en la literatura reciente de Terapia Ocupacional en la región, para entrever en esta producción nuevas posibilidades de reflexión crítica con las condiciones sociales actuales, atravesadas por una profundización neoliberal de la vida que, como en el caso chileno, ha vuelto intolerable aquella normalidad que configura nuestros escenarios vitales.

\section{Lo cotidiano en el desarrollo de las terapias ocupacionales latinoamericanas}

Al hablar de producción latinoamericana en Terapia Ocupacional es importante asumir la imposibilidad de una construcción unitaria que nos permitiese asumir una suerte de identidad unívoca y desprovista de tensiones, tanto por la coexistencia de paradigmas dentro del dispositivo de la Terapia Ocupacional, como porque esto que llamamos Latinoamérica constituye un complejo híbrido multicultural, atravesado por experiencias disímiles y múltiples. Lo anterior implica desestimar cualquier asunción o pretensión de una Terapia Ocupacional latinoamericana única o universal (Galheigo, 2014).

Ahora bien, en el caso de la producción latinoamericana de Terapia Ocupacional asociada a corrientes críticas $^{3}$, se ha persistido en el uso del concepto de vida cotidiana, cotidiano o cotidianidad como alternativa que acentúa su carácter histórico, cultural y político, ante una tradición -o un imperialismo teórico (Hammell, 2011)-que ha reproducido globalmente una perspectiva despolitizada e instrumental de la profesión. En una extensa revisión de la literatura reciente producida por terapeutas ocupacionales de Latinoamérica ${ }^{4}$, lo cotidiano aparece

\footnotetext{
${ }^{3}$ Para esta investigación han destacado las producciones teórico-conceptuales sobre el concepto de cotidiano en Brasil, Chile y Argentina, a partir de una revisión que incorporó las principales publicaciones periódicas de la región (Cadernos Brasileiros de Terapia Ocupacional, Revista de Terapia Ocupacional da Universidade de São Paulo, Revista Ocupación Humana (Colombia), Revista Chilena de Terapia Ocupacional, Revista Argentina de Terapia Ocupacional), otros órganos interdisciplinarios y transregionales e incluyó otras publicaciones como libros o conferencias de alcance regional.

${ }^{4}$ Se ha privilegiado la inclusión de investigaciones que consideren lo cotidiano como objeto analítico para dar cuenta de las dimensiones teóricas que se han puesto en discusión en la Terapia Ocupacional, entendiendo este concepto como uno de los fundamentos contemporáneos de la corriente asociada a la Terapia Ocupacional crítica. Por ello no se han incluido algunos materiales que abarcan la vida cotidiana o la cotidianidad como eje articulador de praxis de intervención social y comunitaria de modo aplicado. Puede profundizarse esta veta en el libro Terapias ocupacionales desde el sur. Derechos humanos, ciudadanía y participación (Simó et al., 2016), donde lo cotidiano aparece como escenario primordial de la Terapia Ocupacional y en el cual se expresan estructuras sociales, políticas, culturales, económicas, de género y raza.
} 
en mayor medida como el escenario primordial de intervención de la profesión, desde perspectivas que describen cómo se organiza y modifica la cotidianidad de personas y comunidades. En dicha revisión también encontré una producción de carácter teórico-conceptual-que es la que interesa para este artículo- dirigida a estudiar las diversas relaciones de poder que conforman y producen la cotidianidad, reconociendo en esta una arquitectura política e histórica.

Dentro de esta última dimensión, Gutiérrez (2004) destaca cómo el análisis de las situaciones cotidianas en los procesos de intervención de Terapia Ocupacional evidencia el carácter ideológico que las produce, así como la reproducción de las relaciones de poder que en ellas existen. En la misma línea, Pardo y Silva (2015) destacan la importancia de develar el carácter político de las ocupaciones y de los espacios de cotidianidad, en el entendido de que en estos se expresan las relaciones sociales que producen y reproducen a los sujetos, como lo son las relaciones de género. También en relación al género y la vida cotidiana, Moreno et al. (2018) han enfatizado cómo en la cotidianidad se reproduce un orden de género a través de construcciones simbólicas arquetípicas y roles normativos asociados a dicha construcción. Esto guarda relación con el análisis de Palacios (2016), al evidenciar cómo los diversos agentes de socialización reproducen la cultura que, a su vez, conforma la vida cotidiana como producto social, histórico y político. En un ímpetu similar, aunque desde una crítica económica feminista, en 2019 destaqué cómo en la cotidianidad se reproduce un orden social y económico que requiere de la feminización de ciertas actividades humanas para perpetuar un orden de género falo/capitalocéntrico, como parte de una estructura económica invisibilizada pero fundamental para sostener la vida (Grandón, 2019).

Por su parte, Caro-Vines (2018) subraya cómo la vivencia cotidiana posibilita construir saberes locales y culturales, entendidos como parte del sentido común de los sujetos y, por ende, como una cuestión dinámica que permite concienciar y problematizar las praxis humanas. Desde Argentina, Arias (2017) releva lo cotidiano como materia de análisis e intervención de la Terapia Ocupacional, destacando su carácter dinámico al ser una configuración dada por sus relaciones con el tiempo, el espacio y los objetos; esto último acentúa la dimensión material de la cotidianidad. Además, reconoce que lo cotidiano es una configuración que sostiene la existencia, en tanto corresponde a un lugar en donde los sujetos se producen a sí mismos y a sus relaciones sociales. En este sentido, la vida cotidiana genera saberes culturalmente situados $y$, a la vez, es el escenario en donde los sujetos se reproducen y reproducen constantemente sus relaciones sociales.

En una investigación reciente, Gonçalves et al. (2020) se han referido a la importancia de pensar lo cotidiano en su relación con la ocupación y circulación en la ciudad $^{5}$, relevando que la posibilidad de movilidad en las ciudades guarda relación con las posiciones sociales de los sujetos en su vida cotidiana y que, por tanto, exis-

\footnotetext{
${ }^{5}$ Esta investigación buscó reconocer la movilidad urbana de jóvenes habitantes de favelas, participantes de programas sociales en Rio de Janeiro. Esta circunstancia dio lugar a que un joven retratase mediante fotografías su cotidianidad y movilidad urbana, incluidas en el artículo de Gonçalves et al. (2020).
} 
tiría una dimensión política en la constitución y la posibilidad de circulación de los espacios que se habitan cotidianamente. Así, existiría una relación entre cotidianidad y espacio, cuestión que más allá de constituir una representación local y estática, evidencia cómo el espacio, en tanto construcción histórica y política, sería una producción social en la que se reinscriben relaciones de poder y posibilidades de aparición para los cuerpos.

Finalmente, es necesario destacar el trabajo reciente de Galheigo (2020), quien ha profundizado teóricamente en lo cotidiano con el objetivo de dar densidad al concepto. En su opinión, este constituiría uno de los fundamentos teóricos y epistemológicos de las perspectivas críticas de la Terapia Ocupacional en la región. En su investigación la autora señala que "por medio de lo cotidiano es posible acceder a la experiencia, lo real, lo imaginario, la memoria, los sueños, los sentimientos, las necesidades y los afectos $^{6 \prime \prime}($ p. 8), acentuando una dimensión subjetiva de lo cotidiano que a la vez se constituye a partir de las relaciones históricas, en tanto:

La lectura de lo cotidiano permite también conocer los modos de pensar, actuar y sentir de los sujetos y colectivos; las representaciones que hacen de sus experiencias en medio de la ideología hegemónica que crea instituciones y resulta en una instrumentalización de la vida diaria. (Galheigo, 2020, p. 8)

La cita anterior releva cómo en la cotidianidad de los sujetos y colectivos aparecen representaciones y claves hermenéuticas de lo real, a partir de las hegemonías vigentes, cuestión que asume la subjetividad como una producción permanente en medio de una red de sentidos, representaciones y relaciones de poder. Ante esta perspectiva, Galheigo (2020) remarca la importancia de considerar lo cotidiano desde una perspectiva materialista histórica que reconozca la urdimbre que la clase social sostiene con otras relaciones de poder, formando un entramado complejo en el cual se reproducen sujetos y cotidianos. Así:
Un sujeto se constituye bajo la colo- nialidad del poder, productora de re- laciones intersubjetivas y culturales en el contexto del capitalismo colonial/ moderno, marcadas por procesos de exploración, discriminación y naturali- zación, con base en las diferencias so- ciales, étnicas, generacionales, de gé- nero y de orientación sexual, así como las producidas por disonancias y con- flicto con los patrones hegemónicos de normalidad, capacidad, productividad y legalidad. (Galheigo, 2020, p. 14)

A partir de esta breve revisión es posible sostener que la vida cotidiana posee una textura producida a partir de la urdimbre de una serie de relaciones de poder, como las de género, raza, clase, capacitismo, edad, colonialidad y orientación sexual. A su vez, esta urdimbre estaría producida por relaciones históricas que, en su reproducción, recrearían instituciones, sentidos comunes y condiciones concretas de existencia para los sujetos, configurando así un cierto vínculo con el espacio, el tiempo, los saberes y los objetos, y reinscribiendo permanentemente las relaciones de poder. Con toda esta densidad, la vida cotidiana constituye un sitio privilegiado para la producción de conocimientos que no se

\footnotetext{
${ }^{6}$ Las citas textuales de la obra de Galheigo son traducción propia.
} 
circunscriben a aquellos sistematizados por los discursos de saber científicos, pues en la cotidianidad circula la memoria colectiva, la cultura, el malestar y los sueños comunes, así como los afectos, los deseos y las fisuras al poder.

Como producción histórica, cultural, temporal, espacial, simbólica y material, en la cotidianidad se reproduce una economía política de los cuerpos que establece modalidades específicas de gobierno y subjetivación. Ante ello, ¿qué ocurre cuando la cotidianidad se vuelve intolerable? ¿Qué ocurre cuando la precarización neoliberal secuestra la potencia de la vida para relegarla al plano de la deuda y la supervivencia? (Cavallero y Gago, 2019). ¿Hasta qué punto podemos tolerar la expropiación de nuestra propia existencia? ¿En qué medida es posible, mediante la acción colectiva, negar una cotidianidad cuya textura se ha vuelto intolerable, para producir otra? Esta serie de preguntas -sin respuesta- buscan entrever en la revuelta popular chilena, iniciada en octubre de 2019, la potencia política de la negación de la cotidianidad, en pos de rechazar la extensiva precariedad que el modelo neoliberal produce constantemente como norma (Morini, 2014).

\section{Narrar-nos: la autoetnografía como propuesta metodológica}

En términos metodológicos, se ha desarrollado una autoetnografía, que considera la reflexión sobre la experiencia individual como un modo de producir conocimientos que vuelven indisoluble lo subjetivo y lo objetivo, mediante una narración en primera persona (Blanco, 2012). Por supuesto, una autoetnografía implica reconocer la propia posición en el mundo, así como el lugar de enunciación de quien investiga, reconociendo las tensiones y parcialidades que ello supone. Como sostiene Haraway (1991), la asunción de la parcialidad es un rasgo característico de la epistemología feminista, pues al evidenciar la no-neutralidad y la posicionalidad al momento de producir conocimientos, se niega aquella pretensión de neutralidad y universalidad del conocimiento androcéntrico que asume a un sujeto abstracto y transparente cuya mirada "reclama el poder de ver y no ser vista, de representar y evitar la representación" (p. 324).

Por ello, este trabajo ha sido desarroIlado a partir de mi permanente participación como protestante en las manifestaciones desarrolladas en la ciudad de Santiago de Chile durante la revuelta popular iniciada el 18 de octubre del 2019. Dicha participación ha incluido un archivo fotográfico de 22 manifestaciones y actos culturales de protesta realizados en las comunas de Ñuñoa y Santiago entre el 19 de octubre del 2019 y el 13 de marzo de 2020.

He decidido narrar esta experiencia política tomando como eje conductor la noción de cotidianidad intolerable, puesto que he observado durante la revuelta una negación colectiva de aqueIla normalidad que hemos sostenido, tal vez, por demasiado tiempo. Así, en este trabajo me he urdido junto a mis tensiones y limitantes: mis fotografías y narraciones se tejen junto a las reflexiones que esbozo desde el centralismo de la ciudad del Santiago-urbano, en una posición social de mediano privilegio. Este trabajo busca desestabilizar las formas tradicionales y androcéntricas de producción de conocimiento, poniendo en juego "unos saberes locales, discontinuos, descalifi- 
cados, no legitimados, contra la instancia teórica unitaria que pretende filtrarlos, jerarquizarlos, ordenarlos en nombre de un conocimiento verdadero, en nombre de los derechos de una ciencia que algunos poseerían" (Foucault, 2000, pp. 22).

\section{Cuando lo cotidiano se vuelve intolerable}

Desde el 18 de octubre del 2019, día en que inició la revuelta popular en Chile, no dejaron de realizarse movilizaciones, manifestaciones y actos culturales como protesta a las precarias condiciones de vida que, como en tantos otros sitios del planeta, se han vuelto algo normal. Lo que comenzó como una protesta de estudiantes de secundaria tras un alza de 30 pesos en el transporte público, a los pocos días se contagiaba por doquier, convirtiéndose en un movimiento ciudadano popular y transversal, en tanto por décadas la opresión política no se ha reducido a la clase trabajadora, sino que, como sostuviera Foucault en 1971:

Ahora se está volviendo intolerable para nuevas capas de la sociedad intelectuales, técnicos, juristas, médicos, periodistas, etc.-.Ella pretende ejercerse a través de ellos, con su ayuda o su complicidad pero sin tener en cuenta sus intereses ni, sobre todo, su ideología. Los que se encargan de impartir la justicia, la salud, el saber, la información, empiezan a sufrir, en su propia labor, la opresión de un poder político ${ }^{7}$. (1994, p.195)
Este rápido contagio puede entenderse por su carácter de negativo sobre la activa producción de vidas precarizadas propias del modelo neoliberal, cuyo desarrollo en Chile ha sido uno de los pioneros y más voraces en la región latinoamericana, mediante su abrupta instalación durante la dictadura militar en 1973 (Ruiz, 2019). Si bien ha sido durante el período de transición a la democracia, o posdictadura, en donde el modelo se ha afianzado, en el caso chileno la dictadura militar coincidió con la instalación legal y económica de las bases del neoliberalismo, privatizando y mercantilizando los derechos sociales, cuestión blindada por la aún vigente Constitución erigida en dictadura.

Chile figura como uno de los países más desiguales del mundo, con una alta concentración de la riqueza y el poder (Pérez y Sandoval, 2020), fenómeno que se da a la par de una serie de privatizaciones de derechos básicos tales como el agua, la educación, la salud, el transporte y el sistema de pensiones de vejez. Previo al estallido social, la voracidad del neoliberalismo chileno venía generando una serie de manifestaciones sociales masivas, por lo menos en los últimos 15 años, producto del malestar común asociado a las injusticias sociales y a la poca garantía de derechos sociales por parte del Estado. Como hito de este período puede señalarse la Revolución Pingüina del año 2006, movimiento que convocó a estudiantes de secundaria y buscaba poner fin al lucro en la educación ${ }^{8}$. Tras las reformas insuficientes en la nueva Ley

${ }^{7}$ Agradezco la generosa traducción de Tuillang Yuing-Alfaro de este texto al español, que constituyó el prefacio de la investigación Enquête dans vingt prisons (1971) editada en Paris por Champ Libre, Groupe d'information sur les prisons (GIP), colectivo en el cual Michel Foucault participaba. Esta traducción de Yuing-Alfaro se hizo a partir de Dits et Écrits. Tome /l (Foucault, 1994, pp. 195-197).

${ }^{8}$ Cuestión permitida por la Ley Orgánica Constitucional de Enseñanza, promulgada por el dictador Augusto Pinochet días antes de entregar el poder (Silva, 2007). 
General de Educación, se dio paso en el 2011 a un nuevo movimiento social de estudiantes, esta vez iniciado por universitarios y universitarias que exigían la inversión estatal en el derecho a la educación pública, gratuita y de calidad, y se negaban a su comprensión como bien de consumo (Rifo, 2013).

Las protestas por el derecho a la educación iniciaron un nuevo ciclo para los movimientos sociales chilenos, perseguidos -pero no extintos- brutalmente con la dictadura. Junto con el movimiento estudiantil, diversos colectivos comenzaron a evidenciar las fisuras del modelo desde diversas posiciones: movimientos ecologistas, movimientos por la defensa del agua y los territorios, movimientos feministas, movimientos indígenas, movimientos de la disidencia sexual y movimientos contra el actual sistema privado de administración de pensiones para la vejez. Estos son solo algunos hitos que muestran cómo durante los últimos años el malestar colectivo sobre esta forma de vida se había venido expresando sistemáticamente, pero sin lograr articularse transversalmente. Ante la indiferencia de los aparatos del Estado, ese malestar derivó el 18 de octubre de 2019 en un gran estallido social catalizado por las juventudes, pero que rápidamente se convirtió en un fenómeno transgeneracional.

Figura 1. El pueblo despertó

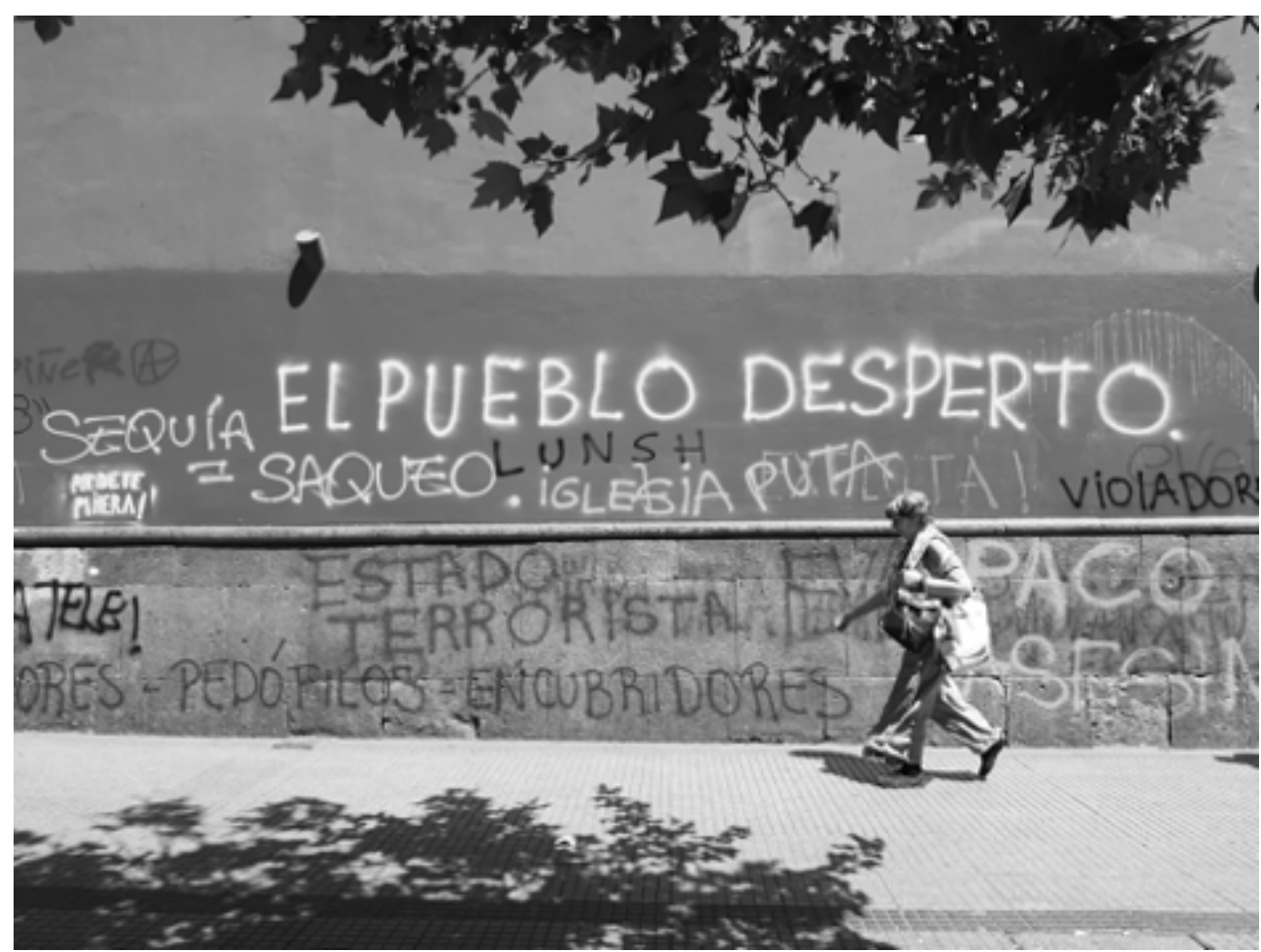

Fuente: fotografía tomada por la autora en la iglesia de San Francisco, ubicada en cercanías de la estación de metro Santa Lucía. 24 de octubre 2019, Santiago de Chile. 
Quizá esta breve perspectiva histórica de la revuelta popular del 2019 nos permita entender porqué una de las consignas más populares durante esos días de octubre era "el pueblo despertó", que aparecía en cánticos, lienzos y muros, como en la primera fotografía (figura 1).

Los días 23 y 24 de octubre se convocó a una huelga general nacional, tras las declaraciones del presidente Sebastián Piñera en las que afirmaba: "Estamos en guerra contra un enemigo poderoso" (Piñera: "Estamos en guerra contra un enemigo poderoso", 2019). Con las brutales medidas de represión, tortura y mutilación que se fueron haciendo cotidianas, supimos que la guerra era contra nosotras: el pueblo. A tan pocos días de iniciada la revuelta, existía una mixtura de cotidianidades superpuestas, mientras se realizaban protestas masivas en el centro de la ciudad, muchas personas seguían intentando sobrellevar su habitual vida laboral en oficinas que debían cerrar anticipadamente por el insoportable gas lacrimógeno; mientras miles de personas continuaban evadiendo el pago del pasaje del transporte público, otras continuaban pagándolo sistemáticamente por obligación moral, por la ascendente criminalización de la evasión, o por ambas.

Recuerdo que por aquellos días recorrí junto con un amigo varios puntos de concentraciones masivas en la ciudad. Usábamos nuestras bicicletas, que más que un simple medio de transporte, poco a poco se volvío un mecanismo de resistencia, una prótesis del cuerpo y un elemento de seguridad que facilitó varias huidas de la represión policial. Como en nuestro caso, el uso de las bicicletas se hizo creciente y común entre manifestantes, y con estas, otros objetos y prácticas empezaron a volverse comunes al habitar, ocupar y producir la ciudad. Para muchas personas era habitual portar agua con bicarbonato -solución que ayuda a mitigar el efecto de las bombas lacrimógenas- para uso personal y solidario; mascarillas o pañuelos para proteger las vías respiratorias de los gases tóxicos; gaza y elementos de curación de heridas; cascos; cámaras fotográficas -como arma de registro y defensa popular-, y protectores oculares.

Terriblemente, este último dispositivo se hizo necesario luego de que quedase en evidencia la sistematicidad con que la policía chilena mutiló los ojos de quienes ejercían su legítimo derecho a la protesta. Al 2020 -y solo pausado por la pandemia-, se registraba un total nacional de 460 víctimas de trauma ocular (EFE, 2020) producto del disparo de balines por parte de efectivos policiales. ¿No resulta una terrible metáfora que sea precisamente el órgano de la vista -y el sentido de la visión- el que resulta mutilado en medio de una revuelta cuya consigna preferente refiere que "el pueblo despertó"? ¿Se puede aniquilar, acaso, la capacidad de una visión nítida sobre las intolerables condiciones de vida mediante la mutilación de los ojos? Los testimonios de Fabiola Campillai y Gustavo Gatica, ambos con ceguera total adquirida producto de una mutilación ocular bilateral, nos muestran que aun con el sentido de la vista arrebatado, la visión -entendida como conciencia- no es algo que pase solo por tener ojos. Y eso, no se puede mutilar.

Así como los nuevos dispositivos y artículos que cotidianamente muchas personas empezamos a llevar entre nuestros enseres, durante la revuelta también se desplegaron relaciones de 
solidaridad, que en una sociedad caracterizada por la atomización, la individualización y la despolitización parecían restringidas a las organizaciones territoriales o a los espacios íntimos de afectividad, más no a la vida cotidiana. Se volvió cada vez más habitual el desarrollo de cabildos ciudadanos en plazas y parques, así como asambleas populares, reinscribiendo nuevas tramas relacionales en los barrios y los territorios a lo largo del país (Albert y Köhler, 2020). La discusión política se tomó las calles y se hizo lengua común por fuera de los partidos políticos y tecnócratas, para ser apropiada por las personas en su vida ordinaria en pos de discutir sobre los soportes materiales de la vida, como la lucha "por el empleo y la educación, por una distribución equitativa de los alimentos, por una vivienda digna, por la libertad de movimientos y la libertad de expresión" (Butler, 2019, p. 77), para poder vivir vidas vivibles (Butler, 2019).

Durante las protestas masivas las redes de solidaridad desbordaron los territorios y se desplegaron en formas diversas en los puntos de concentración masiva de la ciudad. Por ejemplo, grupos de profesionales de la salud co-

Figura 2. Intervención cultural

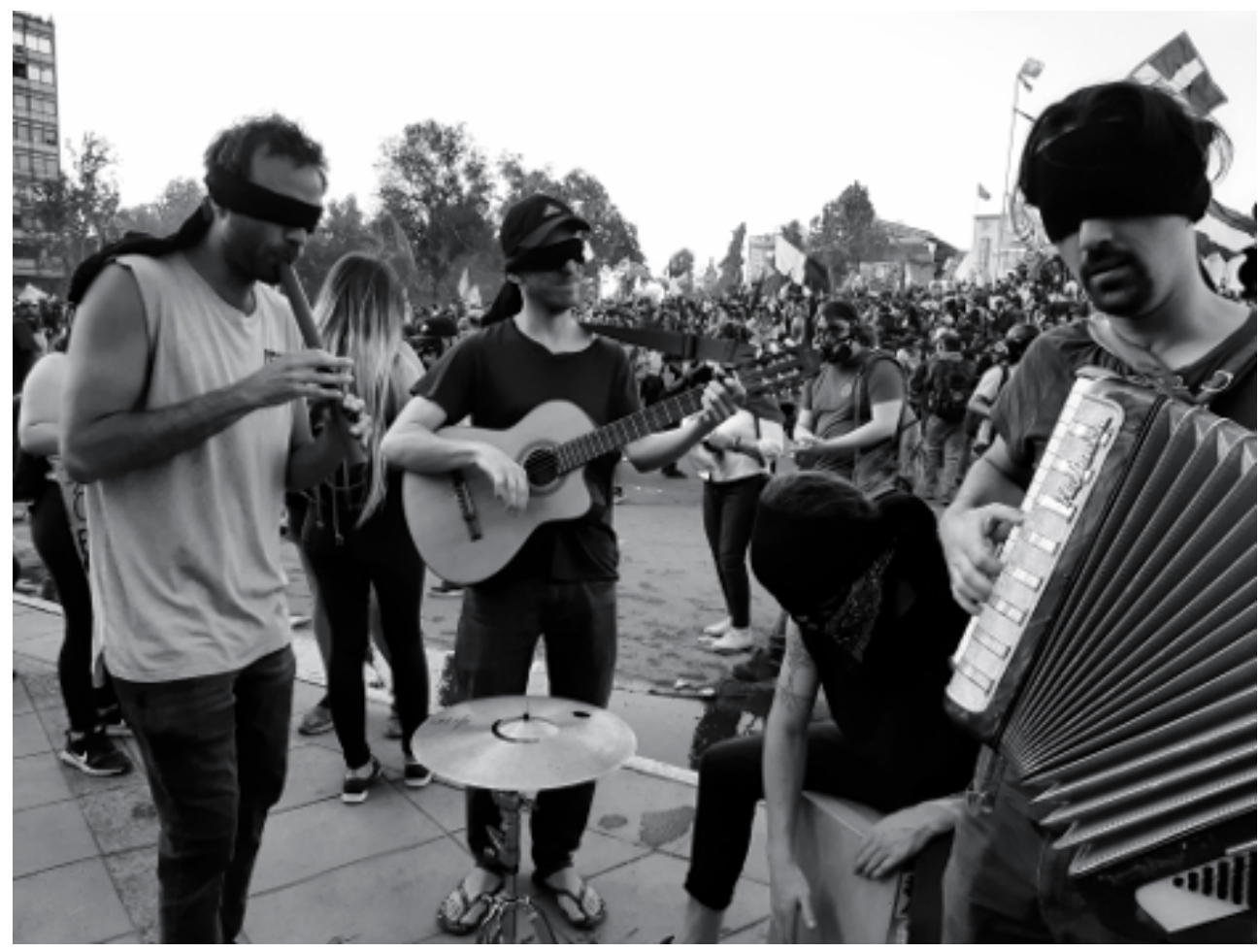

Fuente: fotografía tomada por la autora a un grupo de músicos que participaban de una jornada de protesta con los ojos vendados, simbolizando la mutilación ocular producida por la represión y la violencia policial. Diciembre del 2019, Plaza de la Dignidad, Santiago de Chile. 
menzaron a participar voluntaria y permanentemente en las jornadas de protesta, prestando atención de primeros auxilios y asistencia a personas heridas producto de la represión policial. De manera autogestionada estos equipos fueron estableciendo puntos de atención específicos conocidos por las y los manifestantes. Pese a que estos equipos vestían delantales de salud con Ilamati- vas cruces rojas, aludiendo a su evidente rol de atención de primeros auxilios y asistencia médica, también sufrieron represión policial. Esto condujo a que, incluso, debiesen confeccionar escudos de protección para poder prestar atención de emergencia en la zona cero, punto céntrico y de mayor represión de las manifestaciones en la ciudad de Santiago (figura 3).

Figura 3. Zona cero

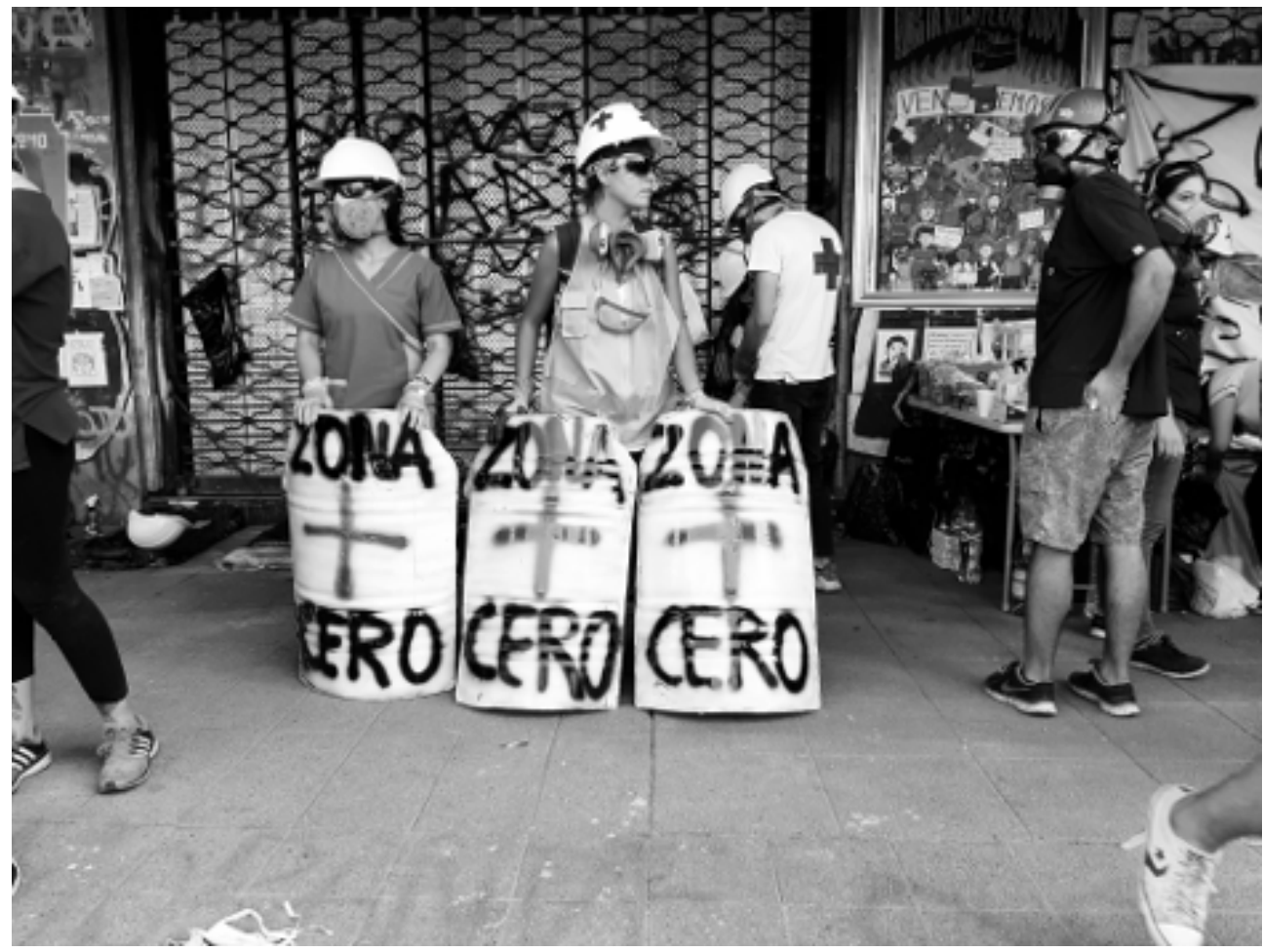

Fuente: fotografía tomada por la autora a personal voluntario de equipos de salud con mascarillas y escudos autofabricados durante la represión con gas lacrimógeno en una protesta. Diciembre del 2019, Santiago de Chile. 
Así como esa red de solidaridad asociada a un saber técnico, la revuelta propició otras acciones de colaboración micropolíticas -que no caben en ninguna foto-. Recuerdo una ocasión en la que asistí sola a una jornada de protesta y entre varias mujeres nos organizamos colectivamente para improvisar un baño en la calle para poder orinar. Entre pañuelos y cuerpos acompañándose en las necesidades vitales, conversé con una mujer de unos 50 años de edad; ella me contó que venía cada viernes junto con otras pobladoras del sector sur de Santiago para hacer ollas comunes y entregar sándwiches a las y los manifestantes de la primera línea ${ }^{9}$ Al compartirme su experiencia, lamentaba no poder asistir todos los días a apoyar las acciones de protesta por su extenuante actividad como trabajadora de casa particular y los largos traslados que ello suponía.

El testimonio de esta mujer me condujo a pensar aquellos movimientos y transformaciones que se dan en lo más capilar, en lo más local, allí donde el poder $-y$ la agencia- opera y se expresa en su singularidad histórica (Foucault, 2000). Según Calderón (1986), uno de los campos para analizar las dinámicas de los movimientos sociales corresponde al de los efectos sociales específicos que estos tienen sobre las relaciones sociales y sobre la sociedad, cuestión producida tanto por la acción colectiva como por el conflicto a través del cual los actores sociales se modifican a sí mismos en las interacciones. Estas modificaciones pueden darse en el orden general de las relaciones de poder y a través de efectos específicos; así se constituyen nuevas culturas cotidianas sobre las bases sociales que las recrearon en primera instancia, modificando la vida en común (Calderón, 1986).

Los movimientos sociales, como motores de la historia, generan nuevas cotidianidades que se expresan en hábitos, costumbres, valores y modos de relación. En el caso de la revuelta popular chilena, además de los cabildos permanentes en lugares públicos y la cotidianización de la discusión política, con el paso del tiempo las tardes de los días viernes se fueron instituyendo como jornadas de protesta sin necesidad de grandes convocatorias ni llamados de movilización, pues parecían volverse una nueva tradición político-popular que conformaba una cotidianidad y una cultura alternativas en varias ciudades de Chile.

En una de esas jornadas, durante los primeros días de diciembre del 2019, me reencontré con un buen amigo que venía viajando desde el sur del país. Concertamos encontrarnos en medio de la masividad, quizá como cuestión poética o política, para reconocernos en el entre social que nos da lugar. Al encontrarnos por fin, luego de meses, nos suspendimos en un abrazo que estremeció nuestros cuerpos al punto de llorar. Al mirarnos, mi amigo intentó enhebrar en una narrativa el mar de sensaciones que le habitaban. Me dijo que habiendo él nacido pocos días antes del golpe militar de 1973, ser parte de esta inédita negación colectiva del orden, 46 años después, era una cuestión que le conmovía profundamente, pues

\footnotetext{
${ }^{9}$ Primera línea es el nombre con el que se conoce al grupo de personas que se enfrentan de manera más directa -en la primera fila-con la represión policial, cuidando así del resto de protestantes e impidiendo el avance de carros lanzaguas (guanacos), vehículos que lanzan gases lacrimógenos (zorrillos), desactivar bombas lacrimógenas disparadas por policías blindados, etc.
} 
había pensado que no lo experimentaría ni sería parte de ello. Sus entrelíneas eran que la revuelta era inevitable, pero que parecía mucho más lejana en el tiempo.

Esta experiencia me hizo pensar en cómo hemos construido tantos mecanismos para soportar el peso de lo cotidiano -a través de políticas, instituciones, prácticas, relaciones y costumbres-, cuya eficiencia nos permitió sostener por varias décadas lo insostenible ${ }^{10}$. Tal como refiere Henri Lefebvre (1972) al señalar que "cuando los individuos, en la sociedad así analizada, ya no pueden seguir viviendo su cotidianidad, entonces comienza una revolución. Solo entonces. Mientras puedan vivir lo cotidiano, las antiguas relaciones se constituyen" (p. 46). Si bien no profundizaré en este punto, es preciso advertir que el endeudamiento ha sido uno de los mecanismos primordiales para sostener esta cotidianidad intolerable, y no me refiero aquí a un endeudamiento en pos de acceso a bienes de consumo lujosos, sino a un endeudamiento estructural en pos de solventar las necesidades básicas como la alimentación o la vivienda (Cavallero y Gago, 2019).

De este modo, la revuelta popular chi- lena iniciada en octubre del 2019 puede pensarse como una pausa para negar lo cotidiano en pos de desestructurar la reproducción material y social de un cierto modo de vida (Lefebvre, 1972). En consignas masivas que emergieron durante este período, tales como "Hasta que la dignidad se haga costumbre" o "Hasta que valga la pena vivir", se observa la interpelación hacia otra vida posible por vivir, una otra vida normal realizada en otros términos y marcos de posibilidad, que para este caso se erigen desde lo digno o lo vivible. Lo que aquí planteo, además de una observación analítica, es un horizonte político por sostener: inicialmente la revuelta se planteó más como un cambio de vida que como un cambio a las superestructuras, como la Constitución, el Gobierno o el Estado (Lefebvre, 1972); con el paso del tiempo esto fue articulándose, en el entendido de que existen condiciones para la vida que no son elegidas y que, sin embargo, pueden disputarse mediante un cambio a las superestructuras.

Ahora bien, es preciso señalar que el reciente Plesbiscito del 25 de octubre de 2020, con su contundente triunfo popular, fue impulsado en un uso político higienizante ${ }^{11}$, en un momento álgido de la

\footnotetext{
${ }^{10}$ No es objeto de este texto analizar los mecanismos de sujeción o de soporte a la cotidianidad neoliberal, aquellos que pese a la precariedad y la explotación hacen vivible una cierta forma de vida, aunque bien el examen crítico de estos mecanismos podría constituir una investigación sumamente relevante de proseguir.

${ }^{11}$ Hago énfasis en el carácter, a mi juicio, higienizante del uso político de este acuerdo en un momento álgido de la revuelta popular, en tanto al momento de firmarlo existían, según la Sociedad Chilena de Oftalmología (BBC News, 2019), un total de 285 víctimas de trauma ocular producto de la represión policial entre el 19 de octubre y el 18 de noviembre del 2019. Este número no cesó, por el contrario, al 20 de marzo del 2020 se contabilizaban 460 víctimas de trauma ocular, acorde con los datos del Instituto Nacional de Derechos Humanos (INDH, 2020). Si bien este organismo reconoce una disminución sustantiva de las lesiones oculares posterior a noviembre, mes en que se firmó el pacto, estas no cesaron, de hecho ascendieron nuevamente durante marzo del 2020 junto a otras formas de violencia como la tortura con y sin violencia sexual hacia hombres, mujeres, niños y niñas (INDH, 2020). El 2 de octubre del 2020, un joven de 16 años fue lanzado por un carabinero desde un puente de 7,4 metros de altura hacia el caudal del río Mapocho en la ciudad de Santiago ( Carabinero arroja a manifestante menor de edad al río Mapocho durante protesta en Chile, 2020). Estos hechos hacen tensionar qué clase de paz —y para quién-garantiza el acuerdo referenciado. Mi crítica apunta a que la paz requiere de condiciones efectivas para producirse, como la justicia o la garantía de derechos sociales.
} 
revuelta y a través de un Acuerdo por la Paz $^{\mathbf{1 2}}$ (Logran histórico acuerdo por una nueva constitución: participación ciudadana será clave, 2019). Este acuerdo fue negociado sin participación popular, principalmente por partidos cercanos al gobierno de Sebastián Piñera y otros sectores que paulatinamente han orientado la demanda por otra vida posible hacia una única discusión técnico-legal alrededor de una nueva constitución. Por supuesto, el cambio de una constitución establecida durante la dictadura militar por una nueva -popular, plurinacional y feminista- es urgente y necesario en pos de trazar otras condiciones de vida en el país; esta será la primera vez que una constitución política en Chile tenga participación popular. Sin embargo, pienso que es necesario advertir las amenazas de cooptación y, en ello, de desarticulación de las demandas populares por sectores tecnocráticos que las pretenden administrar para mantener indemnes los marcos neoliberales que engendran la cotidianidad.

La revuelta popular chilena, al cuestionar la discrepancia entre la experiencia de la vida cotidiana y su expectativa, abre un nuevo imaginario de lo posible a partir de disputarse las perspectivas neoliberales vigentes y disponibles para lo cotidiano. La revuelta afirma otra vida posible que es desconocida, es un sueño colectivo que potencia otra posibilidad para la existencia común. Ante ello, no puedo dejar de referirme a cómo los movimientos feministas han sido uno de los catalizadores de la revuelta tras el Mayo Feminista del 2018, que a su vez tiene décadas de movilizaciones de mujeres y disidencias sexuales en su construcción (Fernández, 2018) (figura 4), y que además figura hoy, a mi juicio, como uno de los proyectos políticos más serios y propositivos ante la actual crisis neoliberal. Los estrechos márgenes de lo posible son ampliados y fracturados por los feminismos, los que, como teoría política y praxis, proponen críticas al proyecto económico y social vigente, buscando establecer otras relaciones cotidianas capaces de sostener la vida y su condición de posibilidad (Pérez, 2014).

La intolerancia colectiva resulta un mecanismo de negación y subversión ante aquellas relaciones y estructuras de poder que reproducen constante e históricamente la precarización y la exclusión. Ante tantos discursos contemporáneos que relativizan al límite, volviendo aceptable lo inaceptable a través de políticas del consenso, lo intolerable puede constituir una clave política de resistencia y agencia que nos permita expandir los estrechos límites de lo posible. Por ello, pienso que la revuelta popular chilena disputa y produce nuevos horizontes para lo cotidiano, con otras texturas, cuerpos, espacios, economías, afectos y deseos, o como afirma Bulo (2020), "este estallido es un brote, en términos de emergencia de la vida, de otra vida, de nuestra otra vida otra vez. Es una insurgencia" (p. 27).

12 Este pacto, acordado sin participación ciudadana, fue realizado el 15 de noviembre del 2019, estableciendo un Plebiscito para votar si se aprueba o se rechaza una nueva constitución política para el país. Es importante señalar que si bien durante las movilizaciones populares la demanda por una nueva constitución fue importante y es de larga data en el pueblo chileno — cuestión que se evidenció en la altísima participación popular en el triunfo de la opción Apruebo-, el gobierno ha pretendido administrar esta demanda poniendo trabas y ambigüedades al proceso, además de no realizar acciones de reparación ni justicia respecto de la gran cantidad de violaciones de derechos humanos en el país. 
Figura 4. Protesta feminista

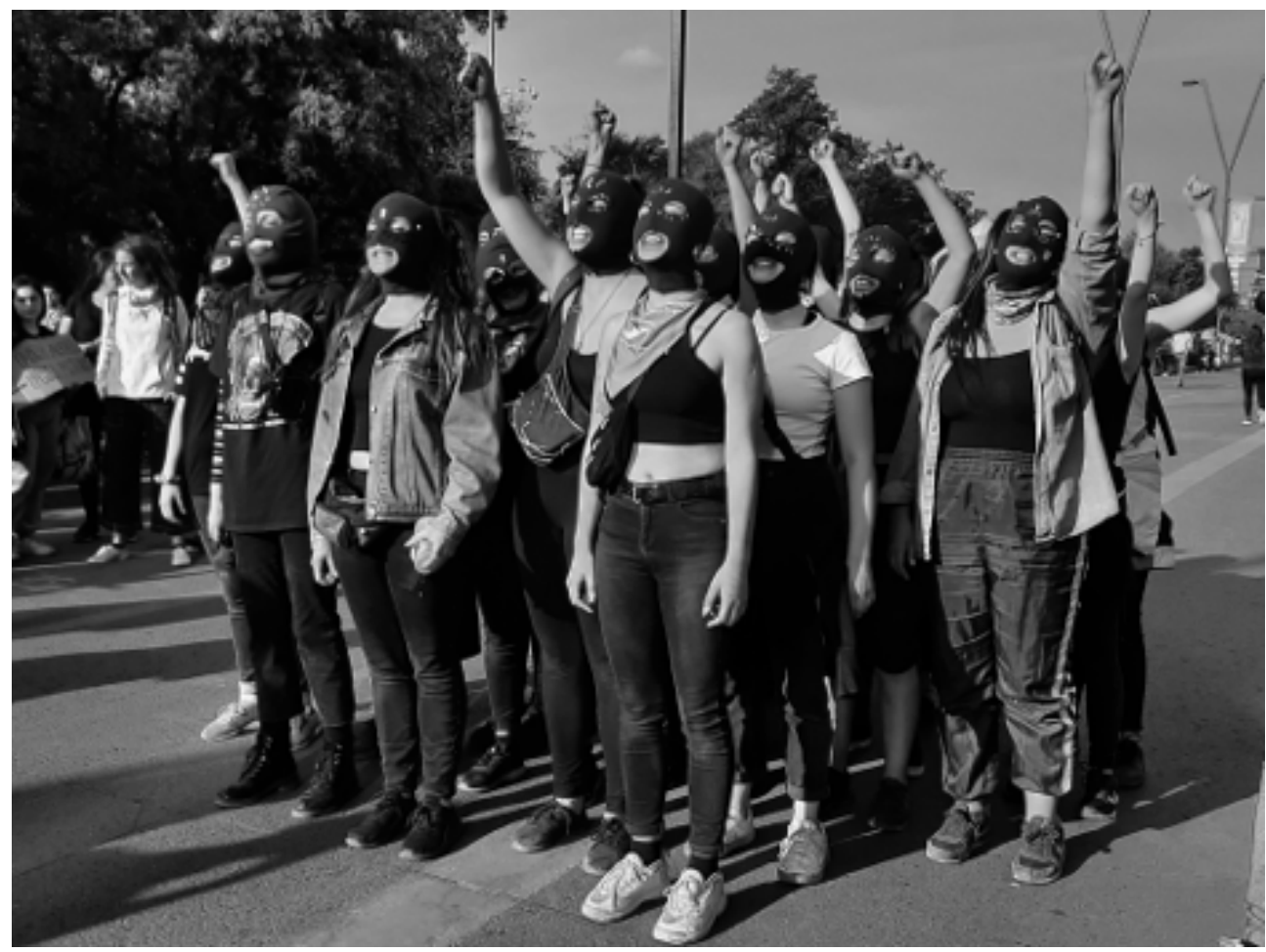

Fuente: fotografía de una acción feminista tomada por la autora en los alrededores de la Plaza de la Dignidad. Octubre del 2019, Santiago de Chile.

\section{La potencia política de la negación}

Durante la revuelta, la densa textura de lo cotidiano ha sido puesta en tensión para operar sobre ella una negación colectiva que pretenda realizarla de otro modo. Ha sido la disonancia entre la vida que se vive y aquella que se proyecta como expectativa (Galheigo, 2020) la que ha alzado un conflicto, un malestar colectivo e histórico que ha evidenciado el carácter intolerable de la cotidianidad. Así como la fotografía (figura 5) apela a que la dignidad se haga costumbre, el análisis de la revuelta popular chilena permite entrever una demanda política que no refiere únicamente a una opresión de clase, sino que al apostar a otra vida por vivir y por hacer posible, con otro contenido, requiere urdir otras relaciones que, en su conjunto, posibiliten una otra cotidianidad.

En este sentido, el desplazamiento epistémico que lo cotidiano posibilita para las terapias ocupacionales latinoamericanas resulta un ejercicio no solo teórico, sino político, en tanto evidencia 
Figura 5. Hasta que la dignidad se haga costumbre

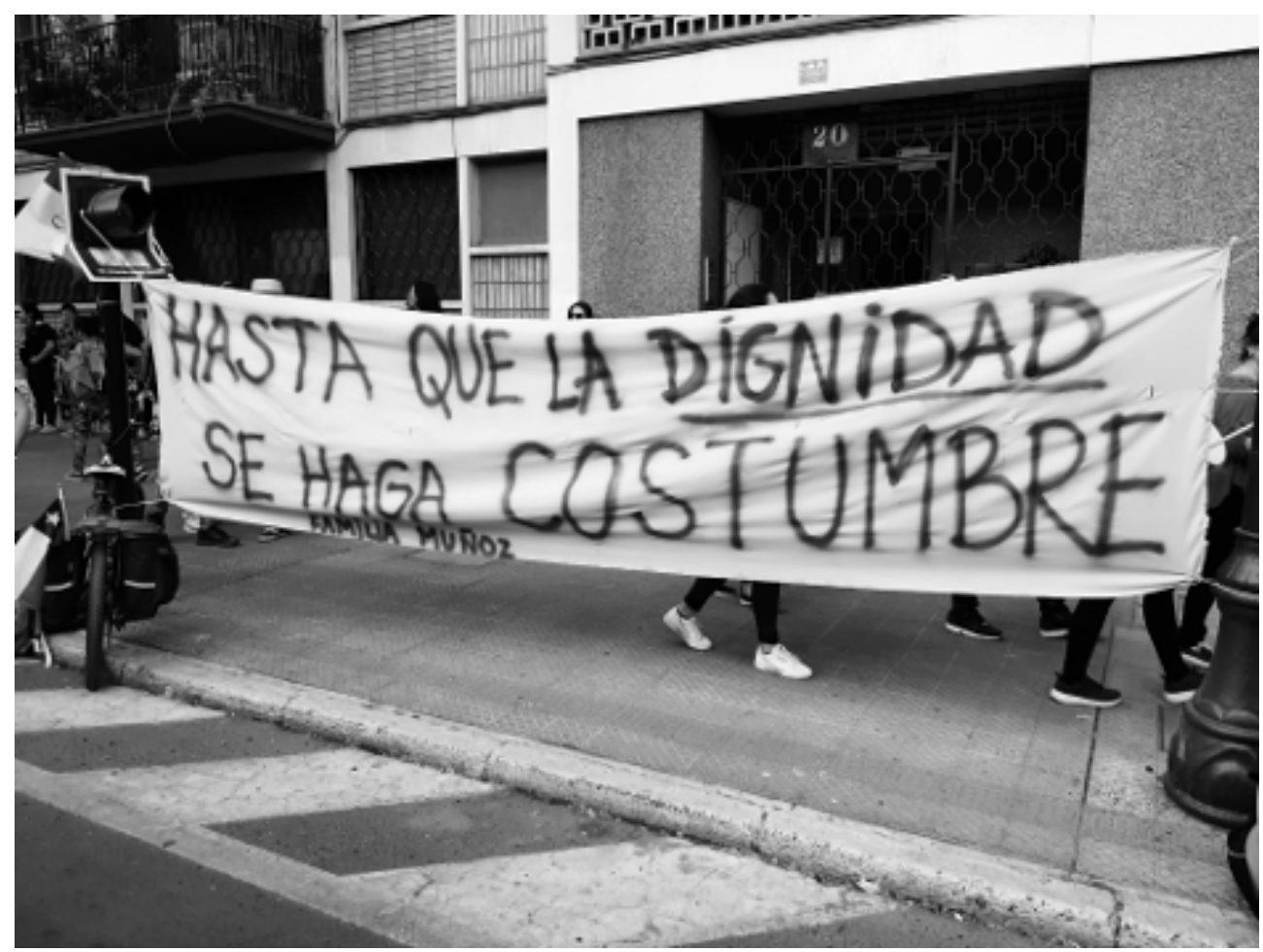

Fuente: fotografía tomada por la autora en la Avenida Seminario del centro de la ciudad durante una manifestación masiva. Octubre del 2019, Santiago de Chile.

la red de relaciones de poder que operan para producir los escenarios vitales de personas, grupos y comunidades. Como sostiene Galheigo (2003, 2012), la vida cotidiana, como concepto y experiencia, permite reconocer la relación entre sujeto e historia para comprender cómo los procesos históricos producen un cierto modo de vida como disponible, que en el caso de la experiencia chilena, ha sido una vida cada vez más precarizada.

La revuelta popular muestra que las ocupaciones humanas colectivas poseen la cualidad de negar y resistir a un cierto orden político para producir otro, en tanto crean las condiciones del mundo que a su vez les produce; cuestión que no está exenta de tensiones. Las condiciones de vida precarias que ofrece el actual modelo neoliberal configuran las posibilidades ocupacionales para los sujetos, trazando ciertas formas de experiencia del tiempo, del espacio, de los bienes culturales y de la existencia misma. Estas experiencias, a su vez, en su reiteración histórica se configuran como normales y, por tanto, tolerables. Esto se reproduce constantemente hasta que se proponen nuevos imaginarios políticos para la vida, a partir de la pausa que abre la negación a lo normal. En este sentido, "las formas que adopta la resistencia política contra la precariedad no convierten la precariedad en igualdad 
económica al instante, pero prefiguran esa conversión, esa revolución, esa posibilidad, y todas ellas funcionan como un Ilamamiento a la movilización" (Butler, 2020, p. 33).

En una profesión que históricamente se ha dedicado a la adaptación de ciertos sujetos considerados anómalos respecto de una cierta norma funcional, el desplazamiento epistémico que ofrece lo cotidiano como experiencia colectiva -y no individual- permite tensionar aquella vida normal en la cual se pretende incluir a grupos y comunidades, la cual está urdida mediante una textura que reproduce permanentemente el racismo, el capacitismo, el sexismo, el colonialismo, el adultocentrismo, el funcionalismo, el productivismo y el especismo ${ }^{13}$ como normalidad. Así, más que propiciar el equilibrio o adaptación de ciertos sujetos a dichos estándares, las terapias ocupacionales encuentran una veta crítica y política en la negación de la cotidianidad que el capitalismo neoliberal configura como única experiencia para la vida, en donde nuestras existencias son constreñidas a devenir capital (Morini, 2014). Esta crítica no debe ser leída como un abandono a la singularidad de cada sujeto en su experiencia, su cuerpo y sus modos de estar en el mundo, más bien, como una necesaria apertura de la Terapia Ocupacional hacia la lucha por la creación de condiciones que permitan vidas vivibles, sostenibles y dignas para sujetos y comunidades.

En suma, esta lectura permite, a lo menos, dos posibilidades epistémicas para la profesión. En primer lugar, evidenciar el potencial político de las ocupaciones y actividades humanas en su capacidad de negarse a lo intolerable para disputar otras condiciones y marcos de posibilidad para la vida. En segundo lugar, el desplazamiento de la Terapia Ocupacional focalizada en la experiencia individual hacia las condiciones colectivas en las cuales se desarrolla la vida, comprendiendo que toda vida posible requiere de condiciones ciertas, de soportes materiales que le permitan desarrollarse y sostenerse (Butler, 2019).

Ahora bien, es importante enfatizar que no solo se requiere garantizar ciertas condiciones para que la vida pueda desarrollarse, cuestión que podría conducir a reproducir las lógicas neoliberales de vidas al mínimo en precariedades que bordean la supervivencia; más bien, que dichas condiciones garanticen vidas vivibles, tal y como sostiene Butler (2019) al decir que "no se trata de conseguir una igualdad que nos haga caer a todos en unas condiciones igualmente invivibles" (73-74).

\section{In-conclusiones: ensanchando los estrechos límites de lo posible}

La insurgencia, la intolerancia y la negación parecen ser enclaves políticos necesarios ante la creciente precarización neoliberal que cada vez más produce existencias dispuestas a trabajar y a devenir capital (Morini, 2014). La negación, a la vez que deja de hacer to-

\footnotetext{
13 El especismo se refiere a la relación de poder antropocéntrica que considera a los seres no humanos como inferiores por pertenecer a otra especie, lo que permite su dominación y utilización. Este término suele utilizarse en los ámbitos de defensa de los derechos de los animales.
} 
lerable aquello que no se debe tolerar, permite movimientos de creación que desestiman las relaciones de poder, produciendo otros cuerpos, otros sujetos, otros vínculos y otros modos de habitar el territorio y la ciudad. Más que solo apelar a la transformación de aspectos parciales de la textura de la cotidianidad, pareciera ser que el momento histórico que enfrentamos a nivel regional e internacional -en donde observamos peligrosas avanzadas del fascismo, los discursos de odio y la precarización a escala global- requiere de negaciones colectivas que se disputen los imaginarios políticos disponibles para nuestra vida común, a la vez que desplieguen prácticas concretas de cooperación.

El gesto político de tomar la revuelta popular chilena como objeto de análisis ha pretendido evidenciar que aquella vida cotidiana en la que hemos aprendido a vivir, y que a la vez hemos aprendido a tolerar, es una figuración histórico-política atravesada por relaciones de poder que, en su reiteración, la vuelven normal. Por ello, la propuesta autoetnográfica, a la vez que comprende otras formas de producir conocimientos desde una perspectiva feminista, ofrece una acción política de desnaturalización de lo cotidiano a partir de su examen crítico.

De todos modos, este trabajo tiene como limitante el ser un ejercicio más bien panorámico respecto del momento coyuntural analizado; podría ser motivo de otras investigaciones un análisis de las demandas populares, las estrategias de acción política del pueblo chileno, los discursos cotidianos en torno a la revuelta o bien las estéticas y símbolos con los cuales se disputan nuevos imaginarios para lo común. Este ejercicio reflexivo de investigación ha buscado tomar la revuelta popular chilena del 18 de octubre como un momento histórico plausible de pensar en clave de lo intolerable, buscando así desestabilizar nuestra comprensión individualizada de las problemáticas sociales y ocupacionales para evidenciar la arquitectura histórica que les produce como tales.

Finalmente, la normalidad que hoy está en disputa es aquella que se ha vuelto intolerable como experiencia vital, y es precisamente aquella potencia del conflicto, de la negación, la que nos abre horizontes políticos para imaginar y producir otras formas de lo común mediante la potencia política de nuestras ocupaciones y acciones colectivas.

\section{Financiación}

Este trabajo se desarrolló gracias al financiamiento de la Agencia Nacional de Investigación y Desarrollo (ANID), mediante la beca PFCHA/Doctorado Nacional 2020 - 21201656. 


\section{Referencias}

Albert, C. y Köhler, T. (2020, 14 de febrero). Yo me organizo en la plaza: las cientos de asambleas que surgieron tras el estallido social. CIPER Chile. https://www.ciperchile. cl/2020/02/14/yo-me-organizo-en-la-plaza-las-cientos-de-asambleas-que-surgieron-tras-el-estallido-social/

Arias, A. (2017). La construcción de lo cotidiano en el tránsito por la heterotopía. Notas sobre la relación sujeto-objeto en las prácticas institucionales. Revista Argentina de Terapia Ocupacional, 3(1), 3-10. http:// www.revista.terapia-ocupacional.org.ar/ RATO/2017jul-art1.pdf

BBC News (2019, 20 de noviembre). Protestas en Chile: la policía anuncia que suspenderá el uso de perdigones en las manifestaciones. BBC News. https://www.bbc.com/ mundo/noticias-america-latina-50483575

Blanco, M. (2012). Autoetnografía: una forma narrativa de generación de conocimientos. Andamios. Revista de Investigación Social, 9(19), 49-74. https://www.redalyc.org/articulo.oa?id=62824428004

Botinelli, M., Nabergoi, M., Mattei, M., Zorzoli, F., Díaz, F., Spallato, N., Mulholland, M., Martínez Del Pezzo, M., García, A., Briglia, J. y Daneri, S. (2016). Reflexiones sobre los orígenes de la formación en Terapia Ocupacional en Argentina. Revista Ocupación Humana, 16(2), 11-25. https:// doi.org/10.25214/25907816.129

Bulo, V. (2020). Afectividades insurgentes. En C. Balbontín y R. Salas (comps.), Evadir. La filosofía piensa la revuelta de octubre de 2019 (pp.23-29). Libros del Amanecer.
Butler, J. (2019). Cuerpos aliados y lucha politica. Hacia una teoría performativa de la asamblea. Paidós.

Butler, J. (2020). Sin miedo. Formas de resistencia a la violencia de hoy. Taurus.

Calderón, F. (1986). Los movimientos sociales ante la crisis. Clacso.

Carabinero arroja a manifestante menor de edad al río Mapocho durante protesta en Chile (2020, 2 de octubre). TeleSur. https://www. telesurtv.net/news/carabineros-manifestante-chileno-rio-mapocho-20201002-0039. html

Caro-Vines, P. (2018). Ocupación: saberes desde la praxis de terapeutas ocupacionales con mayor trayectoria en la región de la Araucanía. Revista Chilena de Terapia Ocupacional, 18(1), 55-72. https://doi. org/10.5354/0719-5346.2018.50367

Cavallero, L. y Gago, V. (2019). Una lectura feminista de la deuda. Fundación Rosa Luxemburgo.

Da Rocha, M. (2008). Terapia Ocupacional: un enfoque epistemológico y social. Ediciones UNL.

EFE (2020, 4 de junio). Víctimas oculares del estallido denuncian "abandono" en medio de la pandemia. El Mostrador. https:// www.elmostrador.cl/dia/2020/06/04/ victimas-oculares-del-estallido-denuncian-abandono-en-medio-de-la-pandemia/ 
Fernández, F. (2018). Nuestro mayo feminista: ¡La revolución será feminista (anticapitalista, anticolonialista) o no será! Iberoamérica Social, 6(X), 28-31. https://iberoamericasocial.com/wp-content/uploads/2018/06/ Fern\%C3\%A1ndez-F.-2018.-NUESTRO-MAYO-FEMINIST.-La-Revoluci\%C3\%B3n-ser\%C3\%A1-feminista-anticapitalista-anticolonialista-o-no-ser\%C3\%A1 ..pdf

Foucault, M. (1994). Dits et Écrits. Tome II. Gallimard.

Foucault, M. (2000). Defender la sociedad. Fondo de Cultura Económica.

Galheigo, S. (2003). O cotidiano na terapia ocupacional: cultura, subjetividade e contexto histórico-social. Revista de Terapia Ocupacional da Universidade de São Paulo, 14(3), 104-109. https://doi.org/10.11606/ issn.2238-6149.v14i3p104-109

Galheigo, S. (2012). Perspectiva crítica y compleja de la terapia ocupacional: actividad, cotidiano, diversidad, justicia social y compromiso ético-político. Revista TOG (A Coruña), 9(5), 176-187. http://www.revistatog.com/mono/num5/compromiso.pdf

Galheigo, S. (2014). Sobre identidades, latinoamericanidades e construção de saberes em Terapia Ocupacional: diálogos com Boaventura de Sousa Santos. Cadernos de Terapia Ocupacional UFSCar, 22(1), 215-221. http://doi.editoracubo.com.br/10.4322/ cto. 2014.023

Galheigo, S. (2020). Terapia ocupacional, cotidiano e a tessitura da vida: aportes teórico-conceituais para a construção de perspetivas críticas e emancipatórias. Cadernos Brasileiros de Terapia Ocupacional, 28(1), 5-25. http://dx.doi.org/10.4322/2526-8910. ctoao2590
Gonçalves, M.V., Neto, L.R.B. y Malfitano, A.P.S (2020). O cotidiano revelado por imagens da cidade. Interface - Comunicação, Saúde, Educação, 24, e190418. https://doi. org/10.1590/Interface.190418

Grandón, D. (2019). Función económica de las ocupaciones feminizadas no remuneradas: una crítica desde la economía feminista. Revista Ocupación Humana, 18(2), 54-67. https://doi.org/10.25214/25907816.228

Guajardo, A. (2014). Debates sobre la producción del conocimiento en Terapia Ocupacional. En contra de una nueva Escolástica. Cuadernos de la Escuela de Salud Pública, 2(88), 33-59. http://saber.ucv.ve/ojs/index. php/rev edsp/article/view/8215/8121

Gutiérrez, P. (2004). Intuiciones en el hacer, reflexiones acerca del quehacer cotidiano en la intervención comunitaria. Revista Chilena de Terapia Ocupacional,(4), 2534. https://boletinjidh.uchile.cl/index.php/ RTO/article/view/159

Gutiérrez, P. y Pujol, J. (2016). Occupational therapy: Autonomy, governmentality and subjectification. Revista de Estudios Sociales, (57), 68-77. https://dx.doi.org/10.7440/ res57.2016.05

Hammell, K.W. (2011). Resisting theoretical imperialism in the disciplines of occupational science and occupational therapy. British Journal of Occupational Therapy, 74(1), 27-33. https://doi.org/10.4276/03080221 1X12947686093602

Haraway, D. (1991). Ciencia, cyborgs y mujeres. La reinvención de la naturaleza. Cátedra.

Heller, A. (1987). Sociología de la vida cotidiana. Península. 
Herrera, M. y Valderrama, C. (2013). Gubernamentalidad y biopolítica: una aproximación con los saberes y prácticas históricas de la terapia ocupacional en Chile. Revista Chilena de Terapia Ocupacional, 13(2), 7992. https://revistaterapiaocupacional.uchile.cl/index.php/RTO/article/view/30218

Herrera, M. y Valderrama, C. (2014). Una visión crítica a la relación entre las condiciones sociopolíticas y los saberes y prácticas de la terapia ocupacional: la situación de Chile. TOG (A Coruña), 11(19), 1-28. http://www. revistatog.com/num19/pdfs/original8.pdf

Instituto Nacional de Derechos Humanos [INDH] (2020, abril). Reporte general de datos sobre violaciones a los derechos humanos. Datos desde 17 de octubre de 2019 e ingresados hasta el 13 de marzo de 2020. INDH. https://www.indh.cl/bb/wp-content/ uploads/2020/04/Reporte-INDH-19-demarzo-de-2020.pdf

Lefebvre, H. (1972). La vida cotidiana en el mundo moderno. Alianza.

Logran histórico acuerdo por una nueva constitución: participación ciudadana será clave (2019, 15 de noviembre). Senado de la República de Chile. https://www. senado.cl/logran-historico-acuerdo-para-nueva-constitucion-participacion/senado/2019-11-14/134609.html

Morini, C. (2014). Por amor o a la fuerza. Feminización del trabajo y biopolítica del cuerpo. Traficantes de sueños.

Moreno, B., Morrison, R., Peña, D. y Reyes, B. (2018). Percepción de la construcción de género en estudiantes de terapia ocupacional: una aproximación al género en la vida cotidiana. Cadernos Brasileiros de Terapia Ocupacional, 26(1), 163-175. https://doi. org/10.4322/2526-8910.ctoAO1124
Palacios, M. (2016). Conceptualizaciones sobre cultura, socialización, vida cotidiana y ocupación: reflexiones desde espacios formativos. Revista Ocupación Humana, 16(1), 5669. https://doi.org/10.25214/25907816.9

Pardo, M. y Silva, G. (2015). Dimensión política de las cotidianidades: implicancias del enfoque de género en las intervenciones de terapia ocupacional. En Colegio de Terapeutas Ocupacionales de Chile, Cincuenta años de terapia ocupacional en Chile: prácticas, epistemologías y realidades locales. Tomo I (pp.113-128). On Demand.

Pérez, A. (2014). Subversión feminista de la economía. Aportes para un debate sobre el conflicto capital-vida. Traficantes de sueños.

Pérez, R. y Sandoval, D. (2020, 26 de febrero). La geografía de la desigualdad y del poder. CIPER Chile. https://www.ciperchile. cl/2020/02/26/la-geografia-de-la-desigualdad-y-del-poder/

Piñera: "Estamos en guerra contra un enemigo poderoso". (2019, 21 de octubre). CNN Chile. https:/www.cnnchile.com/pais/pinera-estamos-en-guerra-contra-un-enemigo-poderoso 20191021/

Rifo, M. (2013). Movimiento estudiantil, sistema educativo y crisis política actual en Chile. Polis. Revista Latinoamericana, 12 (36), 223-240. https://scielo.conicyt.cl/pdf/polis/ v12n36/art10.pdf

Ruiz, C. (2019). La política en el neoliberalismo. Experiencias latinoamericanas. LOM Ediciones.

Silva, B. (2007). La "Revolución Pingüina" y el cambio cultural en Chile. Clacso.

Simó, S., Guajardo, A., Corrêa, F., Galheigo, S. y García, S. (eds.) (2016). Terapias ocupacionales desde el sur: derechos humanos, ciudadanía y participación. USACH. 